\title{
Buschke-Löwenstein tumor in a human immunodeficiency virus-positive patient : a case report and short literature review
}

\author{
V. Ledouble', F. Sclafani², A. Hendlisz'2, M. Gomez Galdon ${ }^{3}$, G. Liberale ${ }^{4}$ \\ (1) Department of Gastroenterology, CHR Citadelle, Liège, Belgium ; (2) Gastrointestinal Oncology Unit, Medical Oncology, Institut Jules Bordet, Bruxelles, Belgium ; (3) \\ Department of Pathology, Institut Jules Bordet, Bruxelles, Belgium ; (4) Department of Surgery, Institut Jules Bordet, Bruxelles, Belgium.
}

\begin{abstract}
Giant condyloma acuminatum, also known as Buschke-Löwenstein tumor, is a rare variant of verrucous carcinoma presenting in the ano-genital region. While its metastatic potential is limited, aggressive local growth is common, with invasion and destruction of the surrounding tissues often causing important therapeutic challenges. Also, data to inform the optimal management approach are scarce and mostly limited to anectodical reports. We present the case of a human immunodeficiency virus-associated locally advanced Buschke Löwenstein tumor that was successfully treated with extensive surgery. (Acta gastroenterol. belg., 2021, 84, 343-345).
\end{abstract}

Keywords : Buschke-Löwenstein tumor, giant condyloma acuminatum, human papillomavirus, squamous cell carcinoma, human immunodeficiency virus.

\section{Introduction}

Giant condyloma acuminatum (GCA) or BuschkeLöwenstein tumor (BLT) was described for the first time in 1925 as a rare variant of verrucous carcinoma presenting in the ano-genital region (1). The incidence of this tumor in the general population is estimated to be about $0,1 \%$, and is most common among young adults, with $2.3: 1$ male to female ratio $(2,3)$.

Human papilloma virus (HPV) infection (especially from low-risk genotypes HPV-6 and HPV-11) and genital warts $(\mathrm{GW})$ are the most important etiopathogenic factors (4). Additional risk factors include smoking, multiple sexual partners, anaerobic infections, local chronic inflammation and immune deficiency (5).

Generally, this tumor arises from the external genitalia, while in only $10-17 \%$ of cases it is localized in the anorectal area (6). Clinical hallmarks include a locally invasive and destructive growh, frequent local recurrence after treatment, and low metastatic potential (2). If left untreated, BLTs can extend into the pelvis, causing disabling symptoms and complications such as fistulisation and abscesses. Some tumors can also transform into more aggressive squamous cell carcinoma (SCC) (7).

The treatment of choice is surgery, other approaches such as radiotherapy and chemotherapy having modest efficacy (6).

Here, we present the challenging case of a locally advanced BLT occuring in a human immunodeficiency virus (HIV) - positive patient.

\section{Case report}

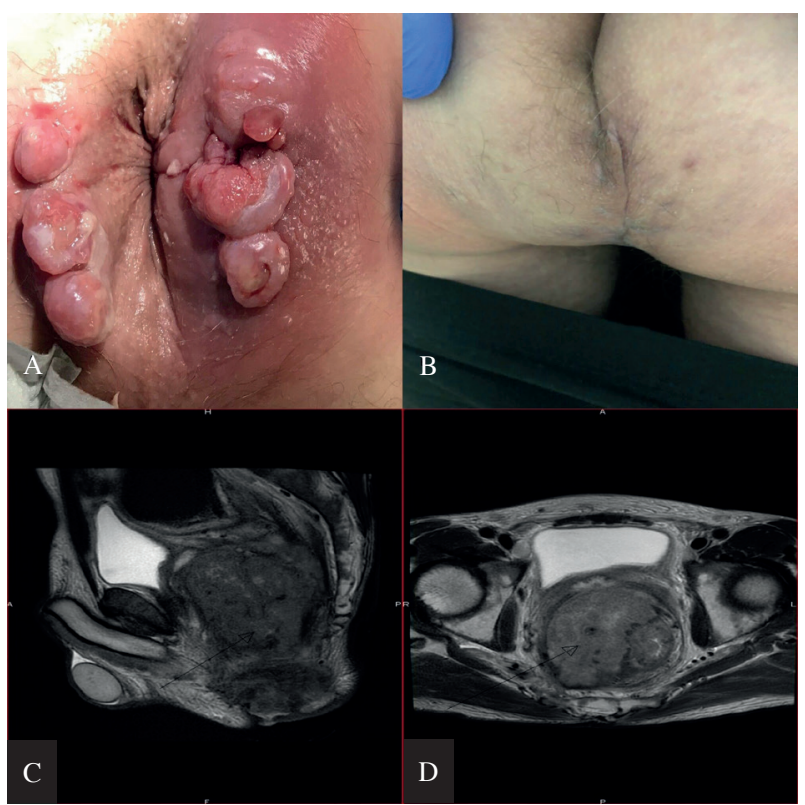

Figure 1. - (A) perianal condyloma with large abcess (before surgery). (B) perianal view 3 months after abdominoperineal resection. (C) Sagittal T2-weighted MRI showing the lesion involving the pelvis floor. (D) Transversal T2-weighted MRI showing the lesion.

A 51-year-old man presented to the local gastroenterology outpatient clinic, complaining of nocturnal anal pain and dysuria for a few days. His medical history included HIV infection since 2011, resection of GWs, anal intra-epithelial neoplasia (AIN) II in 2013 and AIN I in 2014, hepatitis C infection in 2015 treated successfully with Sofosbuvir and Daclatasvir, syphilis infection and proctitis from chlamydia trachomatis and neisseria gonorrhea. He was an active smoker, snorting cocaine on occasion. Regular medications included lormetazepam, raltégravir and emtricitabine/tenofovir.

Physical examination revealed a large, exophytic, cauliflower-like perianal verrucous tumor extending to

\footnotetext{
Correspondence to : Vinciane Ledouble, Boulevard du XII de Ligne I, 4000 Liège, Belgium. Fax : 04/321 8720.

E-mail : Vinciane.ledouble@chrcitadelle.be

Submission date : $21 / 10 / 2020$

Acceptance date : 02/12/2020
} 


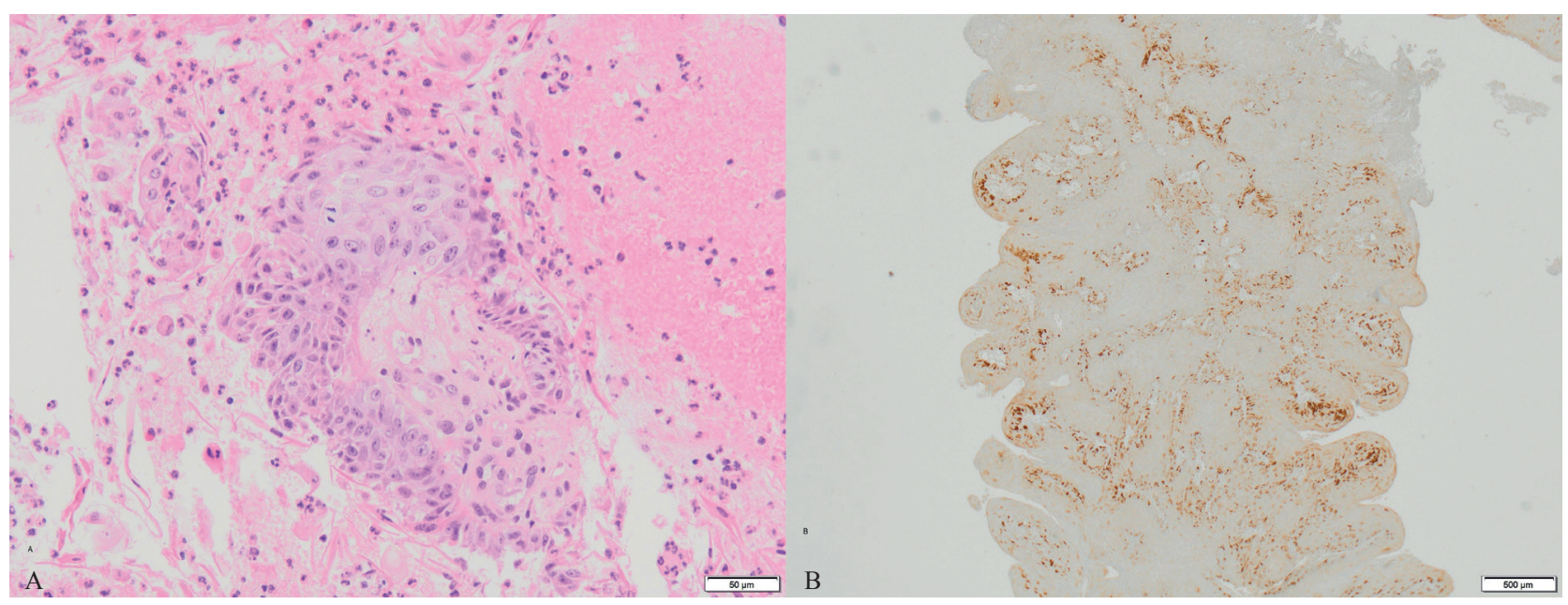

Figure 2. - (A) A papillary structure showing in the basal and the medium layer nuclear atypia and pleomorphism. There are mitosis in the medium layer. (original magnification x 200 ) (B) The scoring of p16 generally includes both nuclear and cytoplasmic staining, and is graded as 1 (rare singly dispersed cells staining). (original magnification x 20)

the right cheek with induration and erythema suggestive of an abscess (Figure 1).

A blood test showed microcytic anemia $(11,3 \mathrm{~g} / \mathrm{dl})$, thrombocytosis $\left(539 \times 10^{3} / \mathrm{uL}\right)$, leukocytosis $(15,810 / \mathrm{uL}$, neutrophils 8,440 cells/uL) and high C-reactive-proteine $(98.3 \mathrm{mg} / \mathrm{L})$. HIV viral load was indetectable, while CD4 count was $500 / \mathrm{uL}$.

An abdomino-pelvic CT scan suggested sigmoidorectitis with right para-rectal and anal abscesses. An MRI of the pelvis revealed a large tumor in the right para-rectal region $(7 \mathrm{~cm} \times 8 \mathrm{~cm} \times 14 \mathrm{~cm})$ with diffuse infiltration of the rectal wall and extension into the subcutaneous tissues, and a small $(1 \mathrm{~cm})$ right inguinal adenopathy (Figure 1C, 1D). An ${ }^{18}$ F-FDG PET-CT scan was also carried out, which confirmed a large hypermetabolic mass (SUV max 24) in the right para-rectal region and along the anal canal, as well as moderately hypermetabolic inguinal and external iliac lymphadenopathies. Finally, an endorectal ultrasound showed an extra-sphincteric fistula with an abscess in the prostate bed.

Initial unsuccessful management included antibiotic therapy, repeat surgical incisions and drainage of the abscesses. Further to the persistence of symptoms including weight loss, severe pain and constipation, a discharge colostomy was performed, and the patient was finally referred to our center.

Following a preliminary assessment in the surgical outpatient clinic, the patient case was discussed at our multidisciplinary team (MDT) meeting, where biopsy of the tumor mass was recommended. A number of biopsy attempts were made, and histology was eventually consistent with a p16-positive condyloma and highgrade dysplasia, without evidence of invasive carcinoma (Figures 2A ; 2B (8)). Given the high suspicion of BLT, however, the ultimate MDT decision was to proceed with surgical resection.

An abdominoperineal resection with cystectomy, orthotopic neobladder and vertical rectus abdominis myocutaneous (VRAM) falp reconstruction was performed. In the immediate postoperative period, the patient suffered from hemorrhagic shock due to necrosis of the graft. A repeat surgery was carried out to control the bleeding, remove the graft and perform an omentoplasty.

Pathological examination of the surgical specimen confirmed the diagnosis of BLT of the anal margin infiltrating the rectum and making contact with prostate and bladder (stage pT4NxMx). Surgical margins were clear, and there was no evidence of either vascular or perineural invasion. One year after surgery, the patient is alive and free of disease. (Figure 1B)

\section{Discussion}

In the literature, little information is available regarding the optimal management of BLT. Most of the available evidence is based on case reports and small retrospective series. Nevertheless, the treatment of choice remains surgery with clear margins (6), with the risk of recurrence being as high as $66 \%$, and an overall mortality rate of about $20 \%$ (9). Also, it is generally accepted that early surgical resection of GWs can reduce the risk of BLT development (10).

Other treatments have been described, with the management approach being often influenced by factors such as size and location of the tumor, and prior unsuccessful therapies (11). Chemotherapy alone (generally cisplatin and 5-fluorouracil) or concurrently with radiotherapy has been shown to induce tumor response in some cases (6).Chemoradiotherapy has been proposed to downsize the tumor in patients with malignant transformation of BLT(2). Intra-arterial chemotherapy with agents such as methotrexate has been successfully used in verrucous carcinomas, including those from the ano-genital region (12). Finally, there are some reports suggesting the activity of intralesional or systemic interferon (13), while oral, topical and intra- 
lesional chemotherapy agents have been used with variable success as adjuvant treatments after surgery or for the management of recurrent tumors (7).

Our case highlights the challenges that physicians may encounter during the diagnostic work-up of BLT as well as the importance of an MDT-driven approach. Despite multiple unsuccessful biopsy attempts, a diagnosis of BLT was suspected based on patient risk factors (smoking, multiple sexual partners, HIV infection), the presence of GWs, and the local invasiveness of the tumor. While upfront surgery implied an extended and mutilating resection to achieve clear margins, it was considered as the most appropriate treatment to promptly relieve local symptoms and to offer the best chances in terms of oncological outcomes. Other options, such as chemoradiotherapy or chemotherapy alone (either before or instead of surgery) were not taking into account in view of the large size of the lesion, multiple abscesses, and severe symptoms.

\section{Conclusion}

BLTs are rare tumors posing significant diagnostic and therapeutic challenges. While surgery with clear margins remains the standard treatment, an MDT-driven management approach should always be adopted.

\section{Conflict of interest}

No conflicts of interest regarding the publication of this paper.

\section{References}

1. BUSCHKE A., LÖWENSTEIN L. Über carcinomahnliche condylomata acuminata des penis. Klinische Wochenschrift 1925, 4 : 1726-8.

2. AHSAINI M., TAHIRI Y., TAZI M.F., ELAMMARI J., MELLAS S., KHALLOUK A. et al. Verrucous carcinoma arising in an extended giant condyloma acuminatum (Buschke-Löwenstein tumor) : a case report and review of the literature. Journal of Medical Case Reports. 2013, 7 : 273.

3. KIM H.G., KESEY J.E., GRISWOLD J.A. Giant anorectal condyloma acuminatum of Buschke-Löwenstein presents difficult management decisions. Journal of Surgical Case Reports. 2018, $4: 1-4$.

4. GARLAND S.M., STEBEN M., SINGS H.L., JAMES M., LU S., RAILKAR $\mathrm{R}$ et al. Natural history of genital warts : analysis of the placebo arm of 2 randomized phase III trials of a quadrivalent human papillomavirus (types 6 , 11, 16, and 18) vaccine. J. Infect. Dis. 2009, $199: 805-814$.

5. SPINU D., RADULESCU A., BRATU O., CHECHERITA I.A., RANETTI A.E., MISCHIANU D. Giant condyloma acuminatum-Buschke lowenstein disease- a literature review. Chirurgia 2014, 109 : 445-450.

6. BEN KRIDIS W., WERDA I., CHARFI S., TOUMI N., BOUDAWARA T., MZALI R. et al. Buschke-Löwenstein anal tumor : an ambiguous entity. Exp. Oncol. 2019 41, 2 : 182-184.

7. SHENOY S., NITTALA M., ASSAF Y. Anal carcinoma in giant anal condyloma, multidisciplinary approach necessary for optimal outcome : two case reports ans review of literature. World J. Gastrointest. Oncol. 2019 February 15, 11(2) : 172-180.

8. GALGANO M.T., CASTLE P.E., ATKINS K.A., BRIX W.K., NASSAU S.R., STOLER M.H. Using biomarkers as objective standards in the diagnosis of cervical biopsies. Am. J. Surg. Pathol. 2010 Aug, 34(8) : 1077-1087.

9. CHU Q. D., VEZERIDIS M. P., LIBBEY N. P., WANEBO H.J. Giant condyloma acuminatum (Buschke-Löwenstein tumor) of the anorectal and perianal regions. Analysis of 42 cases. Diseases of the colon \& Rectum. 1994, 37, no. 9, 950-957.

10. PURZYCKA-BOHDAN D., SZCZERKOWSKA-DOBOSZ A., SWIATECKA-CZAJ J., PEKSA R., URBAN M., SZCZYPIOR M. et al. Buschke-Löwenstein tumour associated with low-risk human papillomavirus genotypes succesfully treated surgically. Adv. Dermatol. Allergol. 2019, XXXVI (1) : 112-114.

11. TRIPOLI M., CORDOVA A., MAGGi F., MOSCHELlA F. Giant condylomata (Buschke-Löwenstein tumours) : our case load in surgical treatment and review of the current therapies. Eur. Rev. Med. Pharmacol. Sci. 2012, $16: 747-751$

12. SANDHU R., MIN Z., BHANOT N. A gigantic anogenital lesion : BuschkeLöwenstein tumor. Case Rep. Dermatol. Med. 2014, 2014 : 650714.

13. GEUSAU A., HEINZ-PEER G., VOLC-PLATZER B., STINGL G., KIRNBAUER R. Regression of deeply infiltrating Giant Condyloma (Buschke-Löwenstein tumor) following long-term intralesional interferon alfa therapy. Arch. Dermatol. 2000 June, 136(6) : 707-710. 